\title{
Percepções e Sentimentos de Gestantes sobre o Pré-natal ${ }^{1}$
}

\author{
Cesar Augusto Piccinini² \\ Fernanda Torres de Carvalho \\ Luciana Rubensan Ourique \\ Rita Sobreira Lopes \\ Universidade Federal do Rio Grande do Sul
}

\begin{abstract}
RESUMO - Foram investigadas percepções e sentimentos de gestantes sobre a assistência pré-natal e se as demandas emocionais eram consideradas no atendimento. Participaram 36 gestantes, 20 a 35 anos, de escolaridades variadas, que responderam a entrevistas sobre a gestação e o pré-natal. Análise de conteúdo revelou a importância do pré-natal, especialmente da ultrassonografia, na redução das preocupações sobre a própria saúde e a do bebê, e no vínculo mãe-bebê. Destacou ainda a importância dos profissionais de saúde, familiares e amigos como fontes de apoio e informação. Contudo, apareceram preocupações sobre a assistência pré-natal e quanto às demandas emocionais, que não foram atendidas. Discute-se a importância de se considerar estas demandas no pré-natal, assim como da humanização deste atendimento.
\end{abstract}

Palavras-chave: gestação, pré-natal, maternidade, sentimentos.

\section{Perceptions and Feelings of Pregnant Women Concerning Prenatal Care}

\begin{abstract}
Perceptions and feelings of pregnant women regarding prenatal care were examined. The extent to which the emotional needs of women were taken into consideration in prenatal care was also investigated. Thirty-six pregnant women, with ages between 20 and 35, of different educational levels, were interviewed about pregnancy and prenatal care. Content analysis showed the importance of prenatal care, particularly obstetric ultrasound, for reducing mothers' worries about their own health and babies' health, as well as for mother-infant attachment. The importance of health professionals, family members and friends' support is also highlighted. Several worries were mentioned, related to medical assistance, and emotional needs, which were not assisted. The need for assistance and the importance of humanization in prenatal care are discussed.
\end{abstract}

Keywords: pregnancy, prenatal care, motherhood, feelings.

A gestação é um momento de grandes transformações, especialmente para as mães primíparas. Ao ser mãe, muitas são as mudanças que se apresentam à mulher em termos físicos, psicológicos, familiares e sociais (Klaus, Kennel \& Klaus, 2000; Maldonado, 1997). Tudo isto passa a estar associado a inúmeros sentimentos que povoam o mundo psíquico das gestantes.

Neste contexto, a assistência pré-natal tem um papel importante, não somente para os cuidados com a saúde das gestantes e seus bebês (Ministério da Saúde, 2001), mas também para as demandas emocionais, tanto da gestante como do pai do bebê. Ela pode servir para a redução de estresse e alívio das tensões (Sable \& Wilkinson, 1999) e para aumentar os sentimentos de segurança da gestante (Ministério da Saúde, 2006a).

A assistência pré-natal é uma modalidade de atendimento originada no século XIX, momento em que teve início a interferência do Estado nas questões relacionadas aos cuidados pré-natais (Ministério da Saúde, 2001). Esse serviço surgiu com o objetivo de contribuir para o desenvolvimento de um recém-nascido saudável e reduzir as elevadas taxas de mortalidade infantil que existiam. Estes objetivos continuam

1 Apoio: $\mathrm{CNPq}$

2 Endereço para correspondência: UFRGS, Instituto de Psicologia, Rua Ramiro Barcelos, 2600/111. Porto Alegre, RS. CEP: 90035-003. E-mail: piccinini@portoweb.com.br. basicamente os mesmos atualmente, sem terem sido incluídos cuidados emocionais da gestação. A atenção pré-natal é fundamental na prevenção de complicações da gravidez, do parto e do puerpério, protegendo a saúde das mães e dos bebês (Ministério da Saúde, 2006a). O início precoce da assistência é indicado, a fim de que se façam possíveis diagnósticos, além da identificação de riscos ligados à saúde da mãe e do bebê (Cook, Selig, Wedge \& Gohn-Baube, 1999; Ministério da Saúde, 2006b).

Uma assistência pré-natal adequada prevê, como mínimo, seis consultas durante o período de gravidez (Ministério da Saúde, 2006b). Se a gestação não é classificada como de alto risco, indicam-se, no mínimo, uma consulta no primeiro trimestre de gestação, duas no segundo e três no terceiro. As gestantes devem ser vistas até atingir o trabalho de parto, ou ser atingido o período de risco para pós-maturidade, em torno da $42^{\circ}$ semana. Para o Ministério da Saúde (2006b), conclui-se a assistência pré-natal somente no $42^{\circ}$ dia após o parto, quando se realiza a consulta de puerpério. Essas determinações podem variar, conforme os riscos apresentados pela gestante, sendo fundamental em todos os casos a adesão à assistência pré-natal (Buchabqui, Abeche \& Brietzke, 2001). Cabe destacar que estas recomendações são basicamente médicas e não mencionam a importância de avaliação e atendimento das demandas emocionais da gestante. Tais demandas são, em alguns casos, contempladas, pelo menos parcialmente, em grupos de apoio as gestantes realizados nos 
centros de saúde, os quais têm se mostrado positivos, ainda que não sejam procedimento universal (Falcone, Mãder, Nascimento, Santos \& Nóbrega, 2005; Souza \& Carvalho, 2003).

De forma geral, alguns fatores tendem a dificultar a adesão das gestantes e de suas famílias à assistência pré-natal, conforme demonstram diversos estudos. Santos, Baroni, Minotto e Klumb (2000) chamaram a atenção para a qualidade da assistência pré-natal como um critério importante para as gestantes na escolha de um local para atendimento. Numa investigação envolvendo 401 mães entrevistadas no pós-parto imediato em Pelotas, os autores encontraram que $85 \%$ dispunham de um posto de saúde como o serviço mais próximo de sua casa. No entanto, $37 \%$ destas não utilizaram esse local para as consultas pré-natais, alegando a má qualidade do atendimento. O estudo de Coimbra et al. (2003) também buscou identificar fatores associados à inadequação do uso da assistência pré-natal em uma comunidade urbana de São Luis, no Maranhão. Para tanto, foram entrevistadas 2.831 puérperas, atendidas em dez unidades de saúde públicas e privadas. Os autores verificaram que a assistência pré-natal inadequada era mais frequente em hospitais públicos e entre gestantes de baixos níveis de escolaridade e de renda familiar.

Além dos fatores associados à qualidade da assistência, a situação socioeconômica tem sido apontada como fator que dificulta a presença das gestantes brasileiras às consultas pré-natais, pelas dificuldades de acesso que essa vulnerabilidade pode acarretar (Silveira, Santos \& Costa, 2001). Somam-se a isto as longas filas, o longo tempo de espera para as consultas, a forma insensível com que alguns profissionais lidam com suas pacientes, a falta de apoio familiar, dificuldades com transporte, diferenças culturais e de linguagem (Cook et al., 1999). Os autores também referem que problemas particulares e sofrimento psicológico, como depressão, ansiedade, estresse ou ambivalência quanto à gestação podem influenciar na adesão à assistência pré-natal (Cook et al., 1999; Sable \& Wilkinson, 1999).

Desta forma, a assistência pré-natal parece ser um momento importante para o oferecimento de apoio emocional e social às mulheres. $\mathrm{O}$ vínculo mãe-bebê é certamente influenciado por fatores externos e contextuais da vida da gestante, sendo um deles o apoio social (Huth-Bocks, Levendosky, Bogat \& Von Eye, 2004). Os autores afirmam que as mães necessitam criar e manter uma rede de apoio para que possam atingir os objetivos da maternidade. Corroborando esses achados, Melender e Lauri (2002) identificaram que problemas relatados por mães norte-americanas durante a gestação estavam associados com o apoio social e com as experiências relacionadas à assistência de saúde pré-natal.

Nesse contexto, os sentimentos das mães em relação à gestação e ao seu bebê são influenciados não só pelo tipo de assistência pré-natal recebida, mas pela sua qualidade e também por procedimentos específicos que são utilizados neste processo. Por exemplo, sabe-se que a realização da ultrassonografia tem um impacto não só na saúde física da mãe e do bebê, mas também em termos emocionais, ao apresentar para a mãe o seu bebê (Fonseca, Magalhães, Papich, Dias \& Schimidt, 2000; Gomes \& Piccinini, 2007a; Piontelli, 2000). Assim, é importante considerar que as questões de saúde física e emocional são aspectos inseparáveis durante esse processo de transição para a maternidade e de assistência pré-natal. Desta forma, considerando a gestação uma fase desenvolvimental marcante na vida da mulher, do bebê e da família e levando em conta a importância da assistência pré-natal neste momento, o objetivo do presente estudo foi investigar as percepções e os sentimentos de gestantes sobre o pré-natal. Busca-se, em particular, examinar em que medida a assistência pré-natal contempla as necessidades emocionais da mãe, além da saúde física da gestante e do bebê.

\section{Método}

\section{Participantes}

Participaram do estudo 36 gestantes que atenderam os seguintes critérios de inclusão: primíparas, com idades entre 20 e 35 anos $(M=26,47)$, de níveis socioeconômicos variados, residentes na região metropolitana de Porto Alegre. Todas viviam com o pai do bebê, não apresentavam complicações de saúde que caracterizassem o pré-natal como de risco, estavam no último trimestre de gestação e realizavam acompanhamento pré-natal. Quanto à escolaridade, as gestantes variavam entre primeiro grau incompleto (11\%) e completo $(5 \%)$, segundo grau incompleto $(3 \%)$ e completo $(22 \%)$, além de terceiro grau incompleto $(22 \%)$ e completo $(36 \%)$. A gestação foi planejada em $67 \%$ dos casos.

A amostra foi selecionada dentre os participantes do "Estudo Longitudinal de Porto Alegre: Da Gestação à Escola - ELPA" (Piccinini, Lopes, Sperb \& Tudge, 1998) que acompanha 81 bebês e suas famílias, desde a gestação até os anos pré-escolares e escolares. O convite inicial para participar do ELPA ocorreu quando a gestante fazia pré-natal em hospitais da rede pública da cidade de Porto Alegre (51\%), nas unidades de saúde do mesmo município (7\%), por meio de anúncios em veículos de comunicação (27\%) e por indicação (15\%). O ELPA foi aprovado pelo Comitê de Ética da Universidade Federal do Rio Grande do Sul. Para fins do presente estudo, foram selecionadas todas as gestantes do ELPA que atendiam aos critérios de inclusão descritos acima.

\section{Instrumentos e procedimentos}

As gestantes que aceitaram participar do estudo responderam inicialmente à Entrevista de Contato Inicial e à Entrevista de Dados Demográficos do Casal, com o objetivo de se obterem dados sociodemográficos (escolaridade, estado civil, moradia, ocupação, religião, grupo étnico, tempo e condições da gestação) e verificar se atendiam aos critérios de inclusão no ELPA. As gestantes incluídas foram informadas sobre os objetivos e os procedimentos do estudo, tendo lido e assinado o Termo de Consentimento Livre e Esclarecido.

Foi então agendado um encontro na casa das gestantes, quando estas responderam à Entrevista sobre a Maternidade e as Expectativas da Gestante, em que foram explorados aspectos da gestação, da relação com o companheiro e com familiares, a reação destes frente à gestação e as expectativas das gestantes com relação ao bebê e à maternidade. Para cada tema, estava prevista uma pergunta geral e diversas questões 
de esclarecimento, utilizadas quando as gestantes não eram explícitas em seus relatos. Para o presente estudo, foram consideradas todas as manifestações das gestantes sobre acompanhamento pré-natal, em particular relatos sobre a sua saúde, ultrassonografias realizadas, profissionais que as atendiam, estado emocional e percepção de apoio. As perguntas que suscitaram essas informações foram: Como te sentiste desde o início da gravidez, em termos físicos e emocionais? Tu tens alguma preocupação em relação à gravidez e ao bebê? Como está a tua saúde, desde o início da gravidez até agora? Quando começaste o teu acompanhamento pré-natal? Como tem sido esse acompanhamento? Já fizeste alguma ultrassonografia? Como foi este momento? Como estás te sentindo, em relação às mudanças do teu corpo? Tens recebido apoio durante a gestação? Que tipo de apoio?

\section{Análise de dados}

Após a leitura exaustiva das entrevistas de todas as gestantes, procedeu-se a uma análise de conteúdo (Bardin, 1979; Laville \& Dione, 1999), a fim de se investigar as percepções e os sentimentos das gestantes acerca da assistência pré-natal, e, em particular, em que medida as demandas emocionais eram consideradas nos atendimentos. A análise foi baseada em quatro categorias temáticas derivadas das próprias entrevistas, denominadas: 1) Contribuições da ultrassonografia no pré-natal; 2) Profissional de saúde como referência no pré-natal; 3) Assistência em saúde como um fator de preocupação para as gestantes; 3) Familiares e/ou amigos como referências na gestação. Dois dos autores do presente estudo classificaram separadamente as manifestações das gestantes nesta estrutura de categorias. Quando ocorreram divergências, estas foram dirimidas por discussão e releitura das entrevistas.

\section{Resultados}

Apresenta-se a seguir, cada uma das categorias, explicitando-as com relatos das próprias gestantes. Cada gestante pode ter apresentado respostas classificadas em mais de uma categoria. Os relatos de diferentes gestantes foram separados por ponto e vírgula. Não foram usados relatos de uma mesma gestante para exemplificar uma mesma categoria.

\section{Contribuições da ultrassonografia no pré-natal}

Os depoimentos da maioria das gestantes (78\%) evidenciaram a importância da ultrassonografia ao longo do período pré-natal, principalmente no que se refere à formação do vínculo com o bebê (67\%), à diminuição das preocupações com a saúde do bebê $(42 \%)$ e à assimilação da gestação (28\%). Quanto à assimilação da gestação, algumas gestantes verbalizaram a importância da ultrassonografia, ao destacarem: "Parecia que não tinha nada. Quando eu olhei o coração assim, parecia aquela confirmação, aquela coisa meio que te dá uma auto-afirmação assim, super legal."; "Eu sempre pensava assim: 'enquanto eu não visse ele na ecografia, eu não acreditava que eu tava grávida.' Eu tinha que ver o nenê ali." Elas mencionaram a importância da ultrassonografia para o reconhecimento da própria maternidade: "Por eu não sentir nada fisicamente, então a única coisa que me dizia: 'eu tô grávida' era quando eu via [na ultrassonografia]."; "Na primeira ecografia, (...) eu não sentia o nenê ainda, né, eu estava com três meses. E aí, quando tu vê a criança, assim, é mais real, né, porque até então era uma coisa mais imaginária".

A ultrassonografia também pareceu auxiliar na formação do vínculo com o bebê, em particular por ter permitido identificar o seu sexo: "E na última [ultrassonografia] eu vou te dizer assim que pra mim foi a mais emocionante, foi quando eu soube que era um guri.";"Ele tinha jeito de homem naquela eco, ele tinha um jeitão com o pé, muito parecido com o do E. [pai do bebê]."; e a identificação de algumas das características físicas do bebê: "O perfil dele [bebê] deu pra ver bem, o tamanho do narizinho, a boquinha dele. Não sei se é bobeira minha, mas eu já imagino o rostinho dele."; "Primeiro ele fez assim com o dedinho, sabe, foi abrindo a mão, esticando o braço. Tipo assim, mãe, olha aqui, eu tenho esse dedinho." A ultrassonografia foi também mencionada em função de proporcionar uma aproximação da mãe com o seu bebê: "Mas a sensação, assim, de tu ver na eco, é, dá mais vontade, assim, de tu pegar, entendeu?"; e do próprio pai com o bebê: “Ah! Me senti super emocionada né, o nenê tava direitinho [na ultrassonografia], tu via o rostinho dele, todo corpinho dele, perfeito né, aí meu marido foi junto né, nós dois estávamos chorando né, é muito emocionante."

A ultrassonografia também se mostrou uma importante forma de diminuir a preocupação das gestantes em relação à saúde do bebê: "[A preocupação] é, no começo, saber se [o bebê] é normal, se vai ter um problema de saúde. Mas depois quando tu vai fazendo a ecografia tu vai vendo que o nenê tá bem."; "Toda vez que eu fazia a ecografia, eu já sabia mais ou menos o que tinha, né. Ah, no início era a formação dos órgãos, né, como tava indo, daí tu fica preocupada, né, se o bebê vai ter alguma anomalia, alguma coisa assim, com um monte de grilo na cabeça, aí depois, agora eu não tô mais tão preocupada".

Juntos, esses relatos demonstram a importância da ultrassonografia para as gestantes, ao revelar o estado de saúde do bebê, ao reduzir as preocupações dos pais, promovendo a construção da própria maternidade e o vínculo com o bebê.

\section{Profissional de saúde como referência no pré-natal}

Nesta categoria, foram incluídos os relatos das gestantes (92\%) que mencionaram profissionais de saúde como referência para elas ao longo do período pré-natal. A maior parte das manifestações estava associada a aspectos de saúde e foi classificada como referências positivas $(80 \%)$ ou negativas (11\%) aos profissionais mencionados. Outra parte das manifestações esteve associada a aspectos emocionais da gestação, e foi também classificada como referências positivas $(30 \%)$ ou negativas (3\%).

Em relação a aspectos de saúde na gestação, evidenciaram-se referências positivas aos profissionais de saúde, como o exemplo: "O meu médico é super cientista, assim, ele gosta de seguir bem à risca todos os exames que tem que fazer, 
todos os meses, então com relação a saúde tá tudo bem.”; “Eu tenho uma médica, uma obstetra que está me acompanhando, e eu tenho mais uma endocrinologista. Eu estou sendo bem acompanhada, em muitos aspectos." Muitas gestantes referiram-se aos profissionais de saúde como importantes fontes de informação a respeito de sua saúde: “Aquele problema de não saber pra quem perguntar né, muitas coisas eu anoto e pergunto pra médica, como o que acontece primeiro: arrebenta a bolsa, dilatação, contração, o que é, o que não é..."; "Eu conversei bastante com a minha obstetra. Ela foi bem legal, bem tranquila comigo. E como eu sou marinheira de primeira viagem, eu pergunto as coisas pra ela."

As gestantes também se referiram de forma negativa aos profissionais de saúde: "O médico, ele é mais assim, ele é assim mais frio, não é muito de conversar, tu não tem... por mais que eu infernize ele, pergunte um monte de coisa, ele é mais quietão."; "Só que o médico é quem não deixou [escolher a forma de parto, ele queria deixar marcada uma cesária]; ele não me deu opção, não me deu outro método [porque ele tinha viagem marcada com a família], eu até entendo o lado dele, mas aí eu troquei de médico e fui pra outro."; "Ela [a médica] é muito seca na hora de dizer as coisas. O M. [marido] sempre foi comigo nas consultas. O M. dizia pra mim: 'Mesmo que eu pergunte, ela dá uma olhada, mas a resposta é pra ti !'Ela não conseguia encarar ele!’.

No que diz respeito aos aspectos emocionais, os profissionais da área da saúde mental foram referidos por algumas gestantes. Salienta-se que, ao serem mencionados, ficou evidente que não se tratavam de profissionais disponíveis como parte do serviço da rotina de pré-natal: "Agora eu quero ver se dou mais uma acalmada, pra ver se eu procuro uma psicóloga pra saber, pois tá sendo difícil assimilar o medo do parto, porque o medo do parto é o pior medo."; "Eu cheguei pro J. [marido]e disse que ia procurar uma psicóloga, fazer uma terapia, porque cada dia tá virando uma coisa na minha cabeça". Por vezes os próprios médicos serviram como referência para as demandas emocionais das gestantes: "A minha médica é especial, sempre foi a ela que eu recorri, porque a gente não tem parentes aqui e como eu não tenho mais mãe, também, né, e ela sempre foi uma mãezona."; "Em relação ao sexo [relações sexuais], às vezes a gente fica um pouquinho alterado, um pouquinho nervosa. Eu já conversei com a médica e ela disse que é normal".

Contudo, ao mencionarem demandas emocionais, algumas participantes referiram-se aos profissionais de saúde de forma negativa: "Daí eu conversei com o meu obstetra, ele pediu uma ecografia pra ver o coração. Ele disse: 'Não, morto não tá'. Ele disse assim, e mesmo se estiver com malformação, um médico não pode chegar e dizer isso pra ti."; "Aí eu falei com a minha endócrino e o que ela me respondeu: 'ah, o teu nenê ou tá morto, ou tá com malformação'. Bem assim ela me respondeu. Daí é aquele negócio é o primeiro filho, tu começa a ficar com aquilo."

Os relatos acima deixam evidente que os profissionais de saúde tinham um importante papel para essas gestantes e que a assistência pré-natal não se restringia a questões médicas ou de saúde física. Profissionais de saúde mental apareceram como importantes, porém como alguém que deveria ser buscado fora do serviço de rotina dos hospitais e postos de saúde. Para além de questões médicas, elas também espe- ravam por apoio as suas demandas emocionais, seus medos e incertezas, o que indica a importância da sensibilidade dos profissionais que as acompanham e de abertura para as demandas emocionais associadas ao pré-natal.

\section{Assistência como um fator de preocupação para as gestantes}

Nas entrevistas, algumas gestantes (25\%) relataram preocupação quanto à assistência em saúde que recebiam na gestação ou iriam receber no parto, especialmente quando a assistência era prestada na rede pública de saúde. Embora este tema não tenha sido diretamente perguntado na entrevista, foi trazido espontaneamente pelas gestantes. Em alguns casos, a preocupação referia-se a algum procedimento durante a gestação (14\%), como a falta de algum exame ou a insatisfação com algum exame realizado. Além disso, dentre as gestantes que tinham preocupações com a assistência, ficou evidente esse sentimento em relação ao parto (17\%).

No que se refere à gestação, algumas preocupações foram evidentes: "Meu médico falou que na vigésima semana de gravidez nós faríamos um exame pra descartar síndromes. Aí, ele tava de férias e acabou passando o tempo e a gente acabou não fazendo."; "Ele [pai do bebê] não pode entrar nas ecografias, eles não deixam um monte de coisas; que a sala é muito pequena, não sei o quê . É tudo desculpa".

Quanto ao parto, algumas referiram estar procurando conhecer hospitais, preocupadas com o local onde iria nascer o bebê: "A gente já tá se agilizando no sentido assim de conhecer os hospitais que a gente não conhecia". A preocupação também seria ligada à possibilidade de ficar sem assistência: "O problema é assim: Ah, aonde que eu vou fazer o meu parto? Vai ter vaga no hospital? E se não tem em nenhum, aonde é que eu vou ganhar?" Além disso, parecia preocupá-las o fato de talvez não terem controle sobre qual o médico que lhes atenderia durante o parto: "A cesárea é marcada pelo próprio doutor, né, e se for parto normal, de repente é outro médico que vai ser; então a gente conversou, pra falar com o doutor, pra ver se pode fazer, né, cesárea."; "Falaram que ia ter uma parteira que ia nos examinar pra ver se tava na hora, eu disse: C. [médico], eu não quero que outra pessoa me examine".

Outro aspecto relacionado ao parto diz respeito ao sistema público ou privado de saúde. Os depoimentos foram claros quanto às diferenças assistenciais percebidas entre os dois sistemas. "Eu tô preocupada, por que eu faço uma idéia diferente de como é o parto num hospital particular e pelo SUS. A gente não vai ter condições de ter num hospital particular, dizem que o atendimento é bem diferente"; "Eu não sei se eu tô enganada, eu posso tá errada, eu não sei se eu acho que pelo hospital particular eles atendem melhor".

\section{Familiares e/ou amigos como referência na gestação}

Ainda que o objetivo principal deste estudo tenha sido investigar as percepções acerca do acompanhamento pré-natal das gestantes, muitas delas (61\%) mencionaram espontaneamente seus familiares e/ou amigos como referências impor- 
tantes na gestação, por contribuírem tanto com informações sobre a gestação e bebê, como pelo apoio emocional que lhes propiciavam. Assim, em função de sua relevância e por terem sido depoimentos frequentes, optou-se por destacar estes relatos nesta categoria.

Quanto às informações recebidas, todas se mostraram satisfeitas. Contudo, quanto aos aspectos emocionais, uma parte delas (33\%) fez referências positivas, enquanto algumas fizeram referências negativas (5\%).

Algumas gestantes referiram-se positivamente a familiares e/ou amigos como importantes fontes de informação sobre a gravidez e em relação a aspectos de saúde: "A minha cunhada, ela é uma doce duma pessoa Eu ligo pra ela: 'Maria, eu tô com falta de ar, será que isso é normal?'(...) 'É normal, porque isso, porque aquilo', então ela é minha segunda mãe de parto, de gravidez."; "Eu ando numa turminha de umas nove amigas e elas começaram 'parto normal tu não sente dor, pois tem uma anestesia no local' e aquilo ficou na minha cabeça, então eu disse tá, vai ser parto normal." Nenhuma das gestantes referiu-se de forma negativa a familiares e/ou amigos, em relação às informações sobre aspectos de saúde.

Quanto aos aspectos emocionais, os familiares e/ou amigos apareceram como referências positivas e importantes fontes de apoio para algumas gestantes: "A gente fica muito abalada na parte emocional. Porque é uma mudança grande para eles [familiares] entenderem. Ele [marido] já dá bastante apoio nessa parte, é parte emocional. Às vezes, eu fico pensando assim, se eu fosse sozinha, ia ser bem mais difícil, né. Eu sempre posso compartilhar com ele tudo, né. É bom ter alguém do lado"; "Ela [irmã] me dá um monte de conselhos pelo telefone, até quando eu achei que tava grávida eu liguei pra ela."

Contudo, outras gestantes mencionaram seus familiares e/ou amigos como referência negativa, em relação a aspectos emocionais: "Dizem assim: 'Ah, agora tu vai ver, vai ficar mal', começam a te botar pilha na tua cabeça, meio que te deixa meio preocupada, né, pô, será que eu não vou agüentar, não vou resistir mesmo, né..."; "A preocupação que eu tinha (...) eu sempre fui cercada por avós, minha mãe, senhoras mais idosas, e diziam, 'não pode fazer isso, não pode fazer aquilo', eu fiquei um pouco com medo; qualquer dorzinha eu ficava com medo já, assim, preocupada."

Os relatos acima indicam a importância do apoio de amigos e/ou familiares durante a gestação, seja quanto às informações sobre a saúde, seja para aspectos emocionais. Contudo, mais do que informações, as gestantes se sentiam satisfeitas por receberem apoio, apesar de que em alguns casos este apoio gerasse um impacto negativo.

Esses depoimentos, em conjunto, demonstram que a assistência no pré-natal e parto pode trazer preocupações para as gestantes, o que acaba por se somar a outras preocupações comumente presentes nesse momento do ciclo vital. Isto ficou particularmente exacerbado entre gestantes que dependiam do SUS para a assistência.

\section{Discussão}

O presente estudo teve como objetivo investigar as percepções e sentimentos de gestantes sobre o acompanhamento pré-natal, e, em particular, em que medida as demandas emocionais eram consideradas no atendimento. Ao falarem sobre o acompanhamento recebido, as participantes salientaram tanto questões de saúde delas e do bebê, como questões emocionais. Nesse processo, foi mencionada a importância da ultrassonografia, de pessoas de referência, como profissionais de saúde, familiares e amigos, além de preocupações com a assistência.

No que se refere aos aspectos físicos, a assistência pré-natal se constitui em um fator fundamental para o desenvolvimento gestacional, como amplamente demonstrado pela literatura (Ministério da Saúde, 2001; 2006a; 2006b). Neste contexto, é importante destacar a presença dos profissionais de saúde que se constituem em principal referência para as gestantes. No presente estudo, as gestantes foram unânimes ao mencionarem o médico como principal referência aos aspectos de saúde da gravidez. O papel destes profissionais será facilitado se pautado pela confiança da gestante em relação a eles (Caron \& Silva, 2002). As participantes do presente estudo deixaram isso claro ao mencionarem que não queriam que outro médico as examinasse ou fizesse seus partos. Além disso, a falta de confiança no profissional se constituiu em motivo para a troca de médico. Assim, os relatos também deixaram evidente a importância de uma boa relação profissional-paciente e da transmissão de informações sobre o processo da gestação e os procedimentos de parto e puerpério. Tiedje (2004) reforça esse aspecto ao afirmar que estabelecer uma relação com a gestante possibilita que as informações não somente sejam transmitidas, mas sejam assimiladas e utilizadas por elas.

Quanto ao apoio emocional, as gestantes do presente estudo relataram que contaram tanto com profissionais de saúde como com familiares ou amigos como fontes de apoio às suas demandas emocionais. Chamou a atenção a importância dos familiares e amigos como pessoas de referência durante o pré-natal, transmitindo informações, dando conselhos, e apoiando a gestante em momentos de instabilidade emocional, o que também tem sido destacado na literatura (Huth-Bocks et al., 2004; Melender \& Lauri, 2002). Contudo, a importância dos familiares não esteve associada apenas a aspectos positivos do apoio recebido, como relatado por algumas gestantes. Para estas, as informações e conselhos recebidos por vezes foram bastante ansiogênicos, perturbando-as mais do que as ajudando, gerando medo em função de cuidados exagerados e em função de experiências negativas prévias de familiares. Nesse sentido, é importante destacar que o apoio social precisa ser pautado na sensibilidade de quem oferece, sob pena de ser percebido como mais negativo do que positivo pela gestante.

Isto também é verdade quando se trata da relação com os profissionais de saúde. Alguns deles foram mencionados no presente estudo como apresentando pouca sensibilidade ao lidarem com questões de saúde da gestante ou do bebê. Nessas circunstâncias, gera-se sofrimento, levando a um impacto emocional negativo. Ao longo das entrevistas, os depoimentos das gestantes deixaram clara a necessidade de apoio emocional durante a gravidez. Esta necessidade fica óbvia, quando se sabe que a gravidez envolve profundas mudanças corporais, psicológicas, familiares e sociais (Klaus et al., 2000; Maldonado, 1997). Assim 
sendo, a presença de um profissional de saúde mental se faz importante no pré-natal, como destacado por algumas gestantes do presente estudo, medos e ansiedades exacerbados poderiam ser adequadamente minimizados por estes profissionais, que podem contribuir não só no apoio psicológico que a gestante necessita, mas também na preparação para a maternidade e, inclusive da paternidade. Neste sentido, cabe aqui destacar a importância dos grupos de gestantes, que têm dado importantes contribuições no pré-natal (Bracco Neto \& Taddei, 2000; Sartori \& Van der Sand, 2004). Ainda que muitos dos grupos tenham um caráter principalmente informativo, tratam-se de um espaço onde as demandas emocionais das gestantes acabam sendo consideradas.

Contudo, no presente estudo, ficou evidente nos relatos das gestantes que não estava previsto no acompanhamento pré-natal o atendimento de suas demandas emocionais. Ao fazerem menção a esses aspectos, as gestantes se referiram à equipe médica, a familiares e amigos, ou à necessidade de buscar apoio emocional fora do serviço de rotina dos hospitais e postos de saúde onde eram atendidas. Considerando a emergência desses temas nas entrevistas, é importante ressaltar a relevância de se constituir um espaço formal e sistemático junto aos locais de atendimento ao pré-natal, a fim de que se tenha um serviço integral à gestante, que não se restrinja a questões de saúde física.

Identificou-se também neste estudo que um dos procedimentos médicos no pré-natal que oferece a oportunidade para a emergência e abordagem de questões emocionais é a ultrassonografia. Ainda que esse exame tenha como objetivo a avaliação de saúde física dos bebês, as participantes também enfatizaram suas implicações emocionais. Assim, a maioria das gestantes mencionou a ultrassonografia como um procedimento importante para a diminuição da preocupação com a saúde do bebê, na assimilação da gestação e na formação do vínculo com o bebê. Esses achados são corroborados pela literatura, em que se vê que a ultrassonografia - procedimento que ainda precisa ser universalizado nos serviços de pré-natal - tem um grande impacto emocional para a gestante, pai e demais familiares (Gomes \& Piccinini, 2007a). Ele torna o bebê mais real e um ator ainda mais presente na relação mãe-bebê, sem falar na sua importância ao transformá-lo também em paciente. (Fonseca et al., 2000; Piontelli, 2000). Assim, a ansiedade com relação à saúde do bebê pode também ser diminuída (Zlotogorsky, Tadmor, Duniec, Rabinowitz \& Diamant, 1996), apesar de algumas vezes ficar exacerbada em função de este exame também poder revelar alguma mal-formação fetal (Gomes \& Piccinini, 2005; Gomes \& Piccinini, 2007b).

Independentemente do que o exame venha a revelar, a ultrassonografia tem importante impacto na relação pais-filho, já que esta relação é construída desde o período pré-natal e vai ter consequências para as relações após o nascimento (Klaus et al., 2000). Desta forma, os relatos das gestantes do presente estudo mostraram a importância da ultrassonografia como um procedimento pré-natal capaz de fortalecer os laços emocionais com o bebê.

Por fim, os depoimentos retrataram a crença de que o atendimento na rede pública de saúde tem menor quali- dade, quando comparado ao atendimento na rede privada. Isso também foi evidenciado em outros estudos realizados no Brasil (Coimbra et al., 2003) e também em outros países, como na Jordânia (Obermeyer \& Potter, 1991) e nos Estados Unidos (Simpson, Korenbrot \& Greene, 1997). Obviamente, os relatos das entrevistas do presente estudo não permitem a avaliação do serviço recebido pelas participantes deste estudo. Porém, é plausível supor que o pré-natal no sistema público brasileiro ainda não seja o ideal. Isto se traduz muitas vezes por um menor número de consultas no pré-natal, apesar da recomendação do Ministério da Saúde (2006b) de um mínimo de seis consultas. Além disto, o parto tende a ser feito por um médico que pode nunca ter visto a gestante anteriormente. Isto acaba por dificultar sua humanização que tem sido enfatizada por instituições e diversos autores (Ministério da Saúde, 2001; 2006a; 2006b; Donelli, 2003, para revisão). Estas características do atendimento pré-natal e do parto no SUS tendem a contribuir para exacerbar as preocupações da gestante durante o pré-natal e possivelmente a reduzir sua adesão ao mesmo, na medida que suas demandas, em particular as emocionais, acabam não sendo atendidas.

Assim, os relatos das gestantes do presente estudo reforçam a necessidade de investimentos na rede pública de saúde, não só na universalização de procedimentos importantes ao pré-natal, mas também no que se refere à humanização do atendimento às gestantes e parturientes (Ministério da Saúde, 2006b; Ramos \& Lima, 2003). Cuidados com a saúde emocional durante o pré-natal, com a presença de profissionais de saúde mental qualificados e com espaço específico para esse tipo de acompanhamento, seriam de grande importância na busca pela efetivação de um dos princípios do SUS, o da integralidade da atenção à saúde, incluindo-se aí sua dimensão emocional.

Cabe ressaltar que características sócio-demográficas e o elevado grau de escolarização de pelo menos parte das participantes do presente estudo podem ter contribuído para relatos mais exigentes e críticos com relação ao pré-natal. Por exemplo, as gestantes mencionaram a possibilidade de mudar de médico(a), de ultra-sonografista e de escolherem o local e a pessoa de referência para o momento do parto, o que não é uma prática comum entre gestantes atendidas pelo SUS. Assim, é possível que essa postura mais crítica de algumas das gestantes entrevistadas contribua para aumentar a qualidade do serviço recebido, com uência positiva para a adesão da gestante ao acompanhamento pré-natal.

Para finalizar, destaca-se a importância de se avaliar sistematicamente a assistência pré-natal às gestantes. Isto pode ser feito abrindo-se um espaço para escutar essas gestantes e também os profissionais envolvidos na assistência. Estas informações são muito importantes para que se aprimore o pré-natal, se possa conhecer as motivações das gestantes que não aderem a ele, e se consiga oferecer um pré-natal de qualidade em termos médicos e psicológicos, para todas as gestantes. Compreender este período, não só é de extrema relevância para as questões imediatas de saúde da própria gestante e do bebê, mas também para a própria maternidade, paternidade e desenvolvimento do bebê. 


\section{Referências}

Bardin, L. (1979). Análise de conteúdo (L. A. Reto \& A. Pinheiro, Trad.). São Paulo: Edições 70/Livraria Martins Fontes. (Original publicado em 1977)

Bracco Neto, H., \& Taddei, J. A. C. (2000). Mudança de conhecimento de gestantes em aleitamento materno através de atividade educacional. Revista Paulista de Pediatria, 18(1), 7-14.

Buchabqui, J. A., Abeche, A. M., \& Brietzke, E. (2001). Assistência pré-natal. In F. Freitas, S. H. Martins-Costa, J. G. Ramos \& J. A. Magalhães (Eds.), Rotinas em obstetrícia (pp. 23-37). Porto Alegre: Artes Médicas.

Caron, O. A. F., \& Silva, I. A. (2002). Parturiente e equipe obstétrica: A difícil arte da comunicação. Revista Latino-Americana de Enfermagem, 10(4), 485-492.

Coimbra, L. C., Silva, A. A. M., Mochel, E. G., Alves, M. T. B., Ribeiro, V. S., Aragão, V. M. F., \& Bettiol, H. (2003). Fatores associados à inadequação do uso da assistência pré-natal. Revista de Saúde Pública, 37(4), 456-462.

Cook, C. A. L., Selig, K. L., Wedge, B. J., \& Gohn-Baube, E. A. (1999). Access barriers and the use of prenatal care by lowincome, inner-city women. Social Work, 44, 129-139.

Donelli, T. M. S. (2003). O parto no processo de transição para a parentalidade. Dissertação de Mestrado, Universidade Federal do Rio Grande do Sul. Porto Alegre.

Falcone, V. M., Mäder, C. V. N., Nascimento, C. F. L., Santos, J. M. M., \& Nóbrega, F. J. (2005). Atuação multiprofissional e a saúde mental de gestantes. Revista Saúde Pública, 39(4), 612-618.

Fonseca, M., Magalhães, J., Papich, H., Dias, R., \& Schimidt, A. (2000). Ultra-sonografia em obstetrícia: Explorando um novo mundo. In N. Caron (Ed.), A relação pais-bebê: da observação à clínica (pp. 97-118). São Paulo: Casa do Psicólogo.

Gomes, A. G., \& Piccinini, C. A. (2005). A ultra-sonografia obstétrica e a relação materno-fetal em situação de normalidade e anormalidade fetal. Estudos de Psicologia, Campinas, 22, 381-393.

Gomes, A. G., \& Piccinini, C. A. (2007a). Impressões e sentimentos de gestantes em relação à ultra-sonografia obstétrica no contexto de normalidade fetal. Psicologia: Reflexão e Crítica, 20(2), 179-187.

Gomes, A. G., \& Piccinini, C. A. (2007b). Impressões e sentimentos de gestantes sobre a ultra-sonografia e suas implicações para a relação mateno-fetal no contexto de anormalidade fetal. Psico, 38(1), 67-76.

Huth-Bocks, A., Levendosky, A., Bogat, A., \& Von Eye, A. (2004). The impact of maternal characteristics and contextual variables on infant--mother attachment. Child Development, 75 (2), 480-487.

Klaus, M. H., Kennel, J. H., \& Klaus, P. H. (2000). Vinculo: construindo as bases para um apego seguro e para a independência. Porto Alegre: Artes Médicas Sul.

Laville, C., \& Dione, J. (1999). A construção do saber: Manual de metodologia da pesquisa em ciências humanas (H. Monteiro \& F. Settineri, Trad.). Porto Alegre: Artes Médicas Sul.

Maldonado, M. T. (1997). Psicologia da gravidez: parto e puerpério. São Paulo: Saraiva.

Melender, H., \& Lauri, S. (2002). Experiences of security associated with pregnancy and childbirth: A study of pregnant women. International Journal of Nursing Practice, 8(6), 289-296.
Ministério da Saúde (2001). Parto, aborto e puerpério: assistência humanizada à mulher. Brasília: Ministério da Saúde.

Ministério da Saúde (2006a). Acompanhamento pré-natal garante gravidez mais segura. Retrieved from http://www.saude.gov.br.

Ministério da Saúde (2006b). Manual técnico: Pré-natal e puerpério, atenção qualificada e humanizada. Série direitos sexuais e direitos reprodutivos. Caderno 5. Brasília: Ministério da Saúde.

Obermeyer, C., \& Potter, J. (1991). Maternal Health Care Utilization in Jordan: A Study of Patterns and Determinants. Studies in Family Planning, 22(3), 177-187.

Piccinini, C. A., Lopes, R. C. S., Sperb, T., \& Tudge, J. (1998). Estudo longitudinal de Porto Alegre: Da gestação à escola. Porto Alegre: Instituto de Psicologia, UFRGS. (Projeto não publicado).

Piontelli, A. (2000). Is there something wrong? The impact of technology in pregnancy. In J. Raphael-Leff(Ed.), 'Spilt milk' perinatal loss \& breakdown (pp. 39-52). Londres: Institute of Psychoanalysis.

Ramos, D. D., \& Lima, M. A. D. S. (2003). Acesso e acolhimento aos usuários em uma unidade de saúde de Porto Alegre, Rio Grande do Sul, Brasil. Cadernos de Saúde Pública, 19(1), 27-34.

Sable, M. R., \& Wilkinson, D.S. (1999). The role of perceived stress on prenatal care utilization: implications for social work practice. Health \& Social Work, 24, 138-146.

Santos, I. S., Baroni, R. C., Minotto, I., \& Klumb, A. G. (2000). Critérios de escolha de postos de saúde para acompanhamento pré-natal em Pelotas, RS. Revista de Saúde Pública, 34(6), 603-609.

Sartori, G. S., \& Van der Sand, I. C. P. (2004). Grupo de gestantes? Espaço de conhecimentos, de trocas e de vínculos entre os participantes. Revista Eletrônica de Enfermagem, 6(2), 153165.

Silveira, D. S., Santos, I. S., \& Costa, J. S. D. (2001). Atenção prénatal na rede básica: Uma avaliação da estrutura e do processo. Cadernos de Saúde Pública, 17(1), 131-139.

Simpson, L., Korenbrot, C., \& Greene, J. (1997). Outcomes of enhanced prenatal services for Medicaid-eligible women in public and private settings. Public Health Reports, 112(2), 122-134.

Souza, R. A., \& Carvalho, A. M. (2003). Programa de Saúde da Família e qualidade de vida: um olhar da Psicologia. Estudos Psicologia (Natal), 8(3), 515-523.

Tiedje, L. B. (2004). Teaching is more than telling: Education about prematurity in a prenatal clinic waiting room. American Journal of Maternal Child Nursing, 29(6), 373-379.

Zlotogorsky, Z., Tadmor, O., Duniec, E., Rabinowitz, R., \& Diamant, Y. (1996). The effect of the amount of feedback on anxiety during ultrasound scanning. Journal of Clinical Ultrasound, 24, 21-24.

Recebido em 01.09.2008

Primeira decisão editorial em 11.01.2010

Versão final em 21.09.2010

Aceito em 21.09.2010 